Summary: Composite materials were prepared by compounding and hot-pressing PP or MAPP and lignocellulosic fibers extracted from the rachis of Musa acuminate Colla var. Dwarf Cavendish banana tree. The fibers were used as raw filler or after a chemical treatment expected to remove most of the extractible compounds. The resulting materials were characterized using SEM, DSC, DMA, tensile tests and water sorption experiments. All results show that the main aspect involved in the interfacial adhesion between the polar filler and the non-polar matrix is the extraction of lignin and fatty substances. This results in higher values of the degree of crystallinity and crystallization temperature of the matrix, higher mechanical properties and lower water sensitivity.

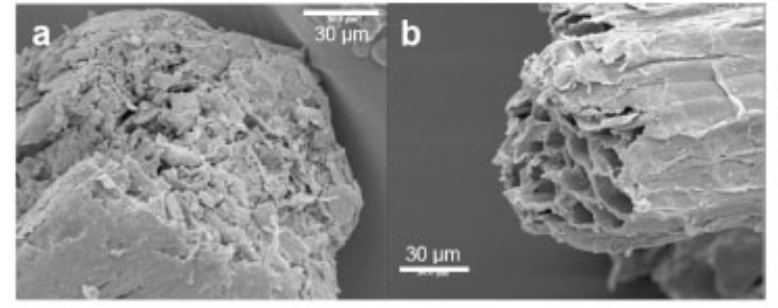

Scanning electron micrograph showing the cross section of the lignocellulosic filler obtained from rachis of banana tree: (a) raw, and (b) extracted fibers.

\title{
Dwarf Cavendish as a Source of Natural Fibers in Poly(propylene)-Based Composites
}

\author{
Helena Faria, ${ }^{1,2}$ Nina Cordeiro,,${ }^{1,2}$ Mohamed Naceur Belgacem, ${ }^{3}$ Alain Dufresne $*^{3}$ \\ ${ }^{1}$ Departamento de Química, Universidade da Madeira, 9000-390 Funchal, Portugal \\ ${ }^{2}$ Centro de Investigação em Ciências Agrárias, Universidade da Madeira, 9000-390 Funchal, Portugal \\ ${ }^{3}$ Ecole Française de Papeterie et des Industries Graphiques, INPG, BP 65, 38402 St. Martin d'Hères, France \\ E-mail: Alain.Dufresne@efpg.inpg.fr
}

Received: June 13, 2005; Revised: September 27, 2005; Accepted: October 14, 2005; DOI: 10.1002/mame.200500212

Keywords: adhesion; composites; Dwarf Cavendish; lignocellulosic filler; poly(propylene) (PP)

\section{Introduction}

Polyolefin polymers, viz. poly(propylene) (PP) or polyethylene (PE), are widely used in automotive industry and for domestic applications when ductility and low cost have to be combined. In these applications, mineral fillers or fibers are extensively used to achieve the desired properties or to reduce the price of the finished article. Polymerinorganic filler composites generally display improved stiffness, strength, hardness, and high temperature creep resistance compared with unfilled polymers. They can also be used to obtain a more competitive price for thermoplastics.

Over the last few years natural fibers have received considerable attention with the possibility of replacing man-made fibers, both in the literature and in industry. ${ }^{[1-3]}$ These natural fibers are mainly based on cellulose and offer well-known advantages of renewability, availability in a variety of forms throughout the world, low energy consumption, low density, inexpensiveness, high specific strength and modulus, low abrasivity ensuring a greater longevity of processing tools and allowing high filling levels resulting in significant cost savings, and easiness of recycling through energy recovery by combustion. One inherent problem is the high variation of mechanical properties due to climatic and growing conditions, the different preparation methods and water absorption. Enhanced properties have been obtained by using natural cellulosic fibers such as sisal,${ }^{[4,5]}$ cotton, ${ }^{[6]}$ bamboo, ${ }^{[7]}$ straw,${ }^{[8]}$ jute, ${ }^{[9]}$ kenaf, ${ }^{[10]}$ wood, ${ }^{[1-14]}$ olive stone, ${ }^{[14]}$ or cladode from Opuntia ficus-indica. ${ }^{[15]}$ As for any multiphase system, properties of natural fibers reinforced composites depend on many factors, for instance fiber/matrix adhesion, volume fraction of fiber, fiber aspect ratio, fiber orientation and stress-transfer efficiency of the interface.

Madeira Island has an extensive area of banana plantations. As one banana plant gives only one bunch of bananas, the bare stems are cut after harvest and usually left in the soil plantation to be used as organic material, leading to high amounts of agricultural residues (ca. 30000 tons/year in 2002). This by-product of banana cooperatives is called rachis. In this context, we recently started a research 
program aimed to study banana plant as a new source of fibers viewing the valorization of this renewable resource in the elaboration of composite materials.

Only few recent studies were reported from Indian research teams on polymers reinforced with banana fibers. ${ }^{[16-23]}$ In these studies, banana fibers were essentially incorporated in thermoset matrices such as novolac resin, ${ }^{[17,20]}$ phenol formaldehyde, ${ }^{[18]}$ or polyester. ${ }^{[19-21,23]}$ Banana fibers were also used as reinforcement for cement-based composites. ${ }^{\text {[24] }}$ Contrarily to Indian production, Musa acuminate Colla var. Dwarf Cavendish represents 50 to $60 \%$ of the whole banana production in Madeira Island.

The aim of the present study was to process and characterize the thermal and mechanical behavior, and water uptake of composite materials composed of a PP matrix reinforced with banana fibers. The effect of the chemical treatment of the filler and the use as matrix of a graft copolymer of PP, maleic anhydride PP (MAPP), expected to promote adhesion between banana fibers (hydrophilic) and the polymeric matrix (hydrophobic) are also described.

\section{Experimental Part}

\section{Materials}

\section{Polymeric Matrix}

PP was provided as pellets by APPRYL. Its melting temperature, degree of isotacticity and density at room temperature were $173{ }^{\circ} \mathrm{C}, 93-98 \%$ and $0.905 \mathrm{~g} \cdot \mathrm{cm}^{-3}$, respectively. MAPP was provided by ELF-ATOCHEM. It contained 1 wt.- $\%$ of maleic anhydride moieties.

\section{Filler}

The experiments were carried out using lignocellulosic fillers extracted from rachis. Two kinds of material were used: (i) the raw material (labeled raw fibers) and (ii) mechanically isolated fibers of rachis obtained from a prototype barking machine of Cavex Company (labeled treated fibers). After air-drying for two weeks, the samples were milled and sieved to 60140 mesh fractions. Rachis was harvested from mature banana trees Musa acuminate Colla var. Dwarf Cavendish in Funchal, Portugal.

The lignocellulosic filler obtained from rachis was also submitted to successive extractions with acetone, ethanol/ toluene $(1: 1 \mathrm{v} / \mathrm{v})$ and water, during 6,8 and $24 \mathrm{~h}$, respectively. The treated material (labeled extracted fibers) was dried at $60{ }^{\circ} \mathrm{C}$ for $3 \mathrm{~d}$ (moisture: $6-7 \%$ ). This treatment was expected to remove most of the lignin and fatty substances.

\section{Composites Processing}

A Brabender FDO 234H model was used to mix and compound lignocellulosic fibers with the polymeric matrix. The fibers were previously dried at $105^{\circ} \mathrm{C}$ (moisture content: $2-3 \%$ ). The compounder was first slowly filled during $5 \mathrm{~min}$ with the polymeric matrix (PP or MAPP), which was allowed to melt at
$200{ }^{\circ} \mathrm{C}$ for $7 \mathrm{~min}$ using a rotor speed of $60 \mathrm{rpm}$. The lignocellulosic filler was then slowly added during $5 \mathrm{~min}$, using a rotor speed of $40 \mathrm{rpm}$, and finally mixed for $5 \mathrm{~min}$ using a rotor speed of $60 \mathrm{rpm}$. Composite materials with fibers content ranging from 0 to $50 \mathrm{wt}$.- $\%$ were prepared.

After mixing, specimens for mechanical properties tests were made by compression-molding the composites. The compounds were hot-pressed at $190{ }^{\circ} \mathrm{C}$ with a CARVER Laboratory Press model 2629. The pressure was first maintained at zero for $25 \mathrm{~min}$ and increased up to $7 \mathrm{MPa}$ (1000 psi) for $5 \mathrm{~min}$.

Laminated composite materials were also processed using treated fibers of rachis obtained from the prototype barking machine. First, two plates of PP with dimensions of $120 \times$ $90 \times 0.6 \mathrm{~mm}$ were separately prepared by hot-pressing PP granules. Hot-pressing conditions consist in a preheating treatment at $190^{\circ} \mathrm{C}$ for $5 \mathrm{~min}$ followed by a hot-pressing stage at $7 \mathrm{MPa}$ for $25 \mathrm{~min}$ at $190{ }^{\circ} \mathrm{C}$. Two sets of treated fibers of rachis $7 \mathrm{~cm}$ long were placed on a PP plate. The first set consisted in parallel fibers and the second set was arranged perpendicularly to the first one. The fibers were fixed at both ends on the PP surface with adhesive tape. Then, the second PP plate was put above the fibers, to form a two layers PP assembly embedding the fibers (sandwich system). This assembly was put in an aluminum mold in order to reduce the flow of PP and thus the fiber misalignment. Then, the sample was hot-pressed at $190^{\circ} \mathrm{C}$. The pressure was first maintained at zero for $10 \mathrm{~min}$ and increased up to $7 \mathrm{MPa}$ for $10 \mathrm{~min}$. This procedure ensured good contact between the fibers and the PP surface.

\section{Characterization Methods}

\section{Scanning Electron Microscopy (SEM)}

SEM was performed to investigate the morphology of the different kinds of fibers and the interface between the filler and the matrix in the composite material with a JEOL JSM-6100 instrument. The specimens were frozen under liquid nitrogen, and then fractured, mounted, coated with gold/palladium on a JEOL JFC-1100 E ion sputter coater and observed. SEM micrographs were obtained using $7 \mathrm{kV}$ secondary electrons.

\section{Thermal Analysis}

DSC (Setaram DSC 92) experiments were performed using ca. $10 \mathrm{mg}$ of the studied material in sealed aluminum capsules placed in a stream of dry nitrogen. Samples were analyzed by heating-cooling cycles between 20 and $210^{\circ} \mathrm{C}$, at a rate of $5 \mathrm{~K} \cdot \mathrm{min}^{-1}$ (for both heating and cooling scans). The melting and crystallization temperatures $\left(T_{\mathrm{m}}, T_{\mathrm{c}}\right)$ were taken as the peak temperatures of the melting endotherm, and crystallization exotherm, respectively, while the heat of fusion $\left(\Delta H_{\mathrm{m}}\right)$ was calculated from the area of the peaks. The degree of crystallinity $\left(X_{\mathrm{c}}\right)$ calculated from DSC thermograms was determined using the relationship:

$$
X_{\mathrm{c}}=\left(\frac{\Delta H_{\mathrm{m}}}{\Delta H_{\mathrm{m}}^{\mathrm{o}}}\right) \cdot\left(\frac{100}{w}\right)
$$

where $\Delta H_{\mathrm{m}}^{\mathrm{o}}=207 \mathrm{~J} \cdot \mathrm{g}^{-1}$ was taken for $100 \%$ crystalline isotactic PP matrix and $\mathrm{w}$ is the weight fraction of matrix in the composite. 


\section{Dynamic Mechanical Analysis (DMA)}

Dynamic mechanical measurements were carried out with a Rheometrics RSA2 spectrometer working in the tensile mode. The specimen was a thin rectangular strip with dimensions of $15 \times 7 \times 0.9 \mathrm{~mm}^{3}$. Tests were performed under isochronal conditions at $1 \mathrm{~Hz}$ and the temperature was varied between 200 and $420 \mathrm{~K}$ by steps of $3 \mathrm{~K}$ and between 420 and $500 \mathrm{~K}$ by steps of $1 \mathrm{~K}$. The narrowing of the temperature increment in the high temperature range was chosen to avoid any sharp variation of the mechanical properties between two measurements. The setup measured the complex tensile modulus $E^{*}$, i.e., the storage $E^{\prime}$ and the loss components $E^{\prime \prime}$, as well as the loss factor $\tan \delta\left(=E^{\prime \prime} / E^{\prime}\right)$.

\section{Tensile Tests}

The nonlinear mechanical behavior of the lignocellulosic filler based composites was analyzed using an Instron 4301 testing machine in tensile mode, with a load cell of $100 \mathrm{~N}$ capacity. The specimen was a thin rectangular strip $\left(15 \times 8 \times 0.9 \mathrm{~mm}^{3}\right)$. The initial length of the specimen between the grips was fixed at $10 \mathrm{~mm}$ and its actual elongation was measured by the movement of the cross-head. Tensile tests were performed at an initial strain rate $\mathrm{d} \varepsilon / \mathrm{d} t=1.7 \times 10^{-3} \mathrm{~s}^{-1}$ (cross-head speed: $1 \mathrm{~mm} \cdot \min ^{-1}$ ) and at $25^{\circ} \mathrm{C}$. The nominal strain $\varepsilon$ was determined by $\varepsilon=\left(L-L_{0} / L_{0}\right)$, where $L$ and $L_{0}$ are the length during the test and the length at zero time, respectively. The nominal stress $\sigma$ was calculated by $\sigma=F / S_{0}$, where $F$ is the applied load and $S_{0}$ is the initial cross-sectional area. Stress-strain curves were plotted and the Young's modulus $(E)$ was deduced from the low strain region.

The ultimate mechanical properties were also characterized: nominal ultimate stress, or nominal stress at break (identified with tensile strength throughout the paper), $\sigma_{\mathrm{b}}=F_{\mathrm{b}} / S_{0}$, where $F_{\mathrm{b}}$ is the applied load at break, and nominal ultimate strain, or nominal strain at break, $\varepsilon_{\mathrm{b}}=\Delta L_{\mathrm{b}} / L_{0}$, where $\Delta L_{\mathrm{b}}$ is the elongation at break. At least five specimens were tested for each set of samples and mean values are reported.

\section{Water Absorption}

The sample dimensions for water absorption experiments were $10 \times 10 \times 1 \mathrm{~mm}^{3}$ and were assumed to be thin enough to consider the molecular diffusion as one-dimensional. A minimum of three samples were tested for each material. After drying overnight at $70^{\circ} \mathrm{C}$, the samples were cooled and weighted, and then stored at $25^{\circ} \mathrm{C}$. Two experimental methods were used:

1. The water absorption of samples was determined when immersed in distilled water at room temperature and $\mathrm{pH}=6$. The samples were removed at specific time intervals, blotted to remove the excess water on the surface and immediately weighed. The water absorption or water uptake $(W U)$ was calculated as

$$
W U(\%)=\frac{\left(M_{\mathrm{t}}-M_{0}\right)}{M_{0}} \times 100
$$

where $M_{0}$ and $M_{\mathrm{t}}$ are the sample weights before and after $\mathrm{t}$ min exposure to water, respectively. Because some samples (raw lignocellulosic filler) have a high content of water-soluble components, an alteration on this classic method was made. After removal and blotting the sample and in order to remove the excess water, it was dried at $105^{\circ} \mathrm{C}$ in a humidity balance (Gibertini, Eurotherm) to determine the water content and minimize the effect of the soluble component extraction.

2. The water absorption was determined by conditioning the sample in a highly moist atmosphere. In this case the sample was stored at $25^{\circ} \mathrm{C}$ in a desiccator containing sodium sulfate to ensure a relative humidity $(\mathrm{RH})$ of $98 \%$. The water absorption was determined using Equation (2). The mass of absorbed water was expressed for short times according to Vergnaud: ${ }^{[25]}$

$$
\frac{M_{\mathrm{t}}-M_{0}}{M_{\infty}}=\frac{2}{L}\left(\frac{D}{\pi}\right)^{1 / 2} t^{1 / 2}
$$

where $M_{\infty}$ is the mass adsorbed at equilibrium, $2 L$ the thickness of the polymeric film and $D$ the diffusion coefficient of water.

\section{Results and Discussion}

\section{Morphological Characterization}

SEM was used to characterize both the structure of lignocellulosic fillers and the morphology of PP-based composite materials.

The SEM micrographs in Figure 1 show the effect of the chemical treatment (extraction step) on the structure of the lignocellulosic filler obtained from rachis. The surface of the raw fibers, around $250 \mu \mathrm{m}$ in diameter, is uneven (Figure 1a). After the extraction treatment (Figure 1c), the diameter of the fibers is decreased around $150 \mu \mathrm{m}$ and it seems that the removal of extractives make the surface of the filler smoother and more ligneous. The cross-sectional observations of both the raw and extracted lignocellulosic filler obtained from rachis are shown in Figure $1 \mathrm{~b}$ and 1d, respectively. The raw material displays a rather compact structure. After removal of extractives, the structure is less compact and cylindrical holes oriented along the fiber axis are clearly observed. They most probably correspond to the localization of extractives, which represent $18 \%$ of the weight of the raw filler. ${ }^{\text {[26] }}$

The mechanically isolated rachis fibers (treated fibers) were also investigated and showed similar features as those found for extracted rachis, except for two main differences: (i) the fibers seem to be thinner after mechanical treatment, and (ii) the surface of the fibers displayed a multi-layer organization of this material (not shown), indicating that the defibrillation process removes a significant amount of components, as observed in a previous work. ${ }^{[26]}$

SEM micrographs of the freshly fractured surface for composite samples are shown in Figure 2 and 3. Figure 2a and $3 \mathrm{a}$ correspond to the surface of fracture for unfilled PP and MAPP matrices, respectively. The rupture was clean 

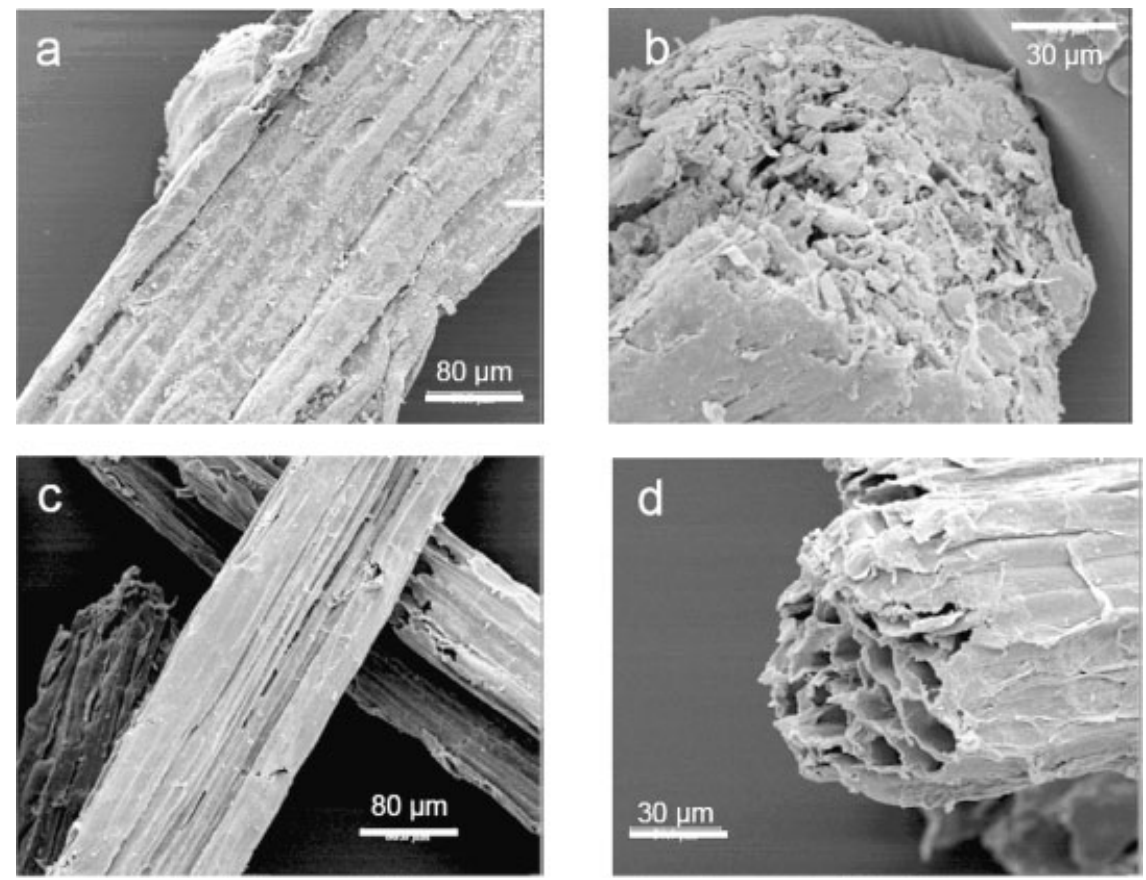

Figure 1. Scanning electron micrograph showing the lignocellulosic filler obtained from rachis of banana tree: (a) raw fibers, plane view, and (b) raw fibers, cross section, (c) extracted fibers, plane view, and (d) extracted, cross section.

and the surfaces are quite smooth and compact. Figure $2 b$ and $2 \mathrm{c}$ correspond to PP-based composites reinforced with rachis: 25 wt.- $\%$ of raw fibers (panel b), and 50 wt.- $\%$ of extracted fibers (panel c). A chaotic rupture can be observed and the sample cleaved under fracture. The raw lignocellulosic filler is pulled out practically intact from the matrix (Figure 2b), i.e. the fracture of the sample did not lead to the lignocellulosic filler break. This observation clearly
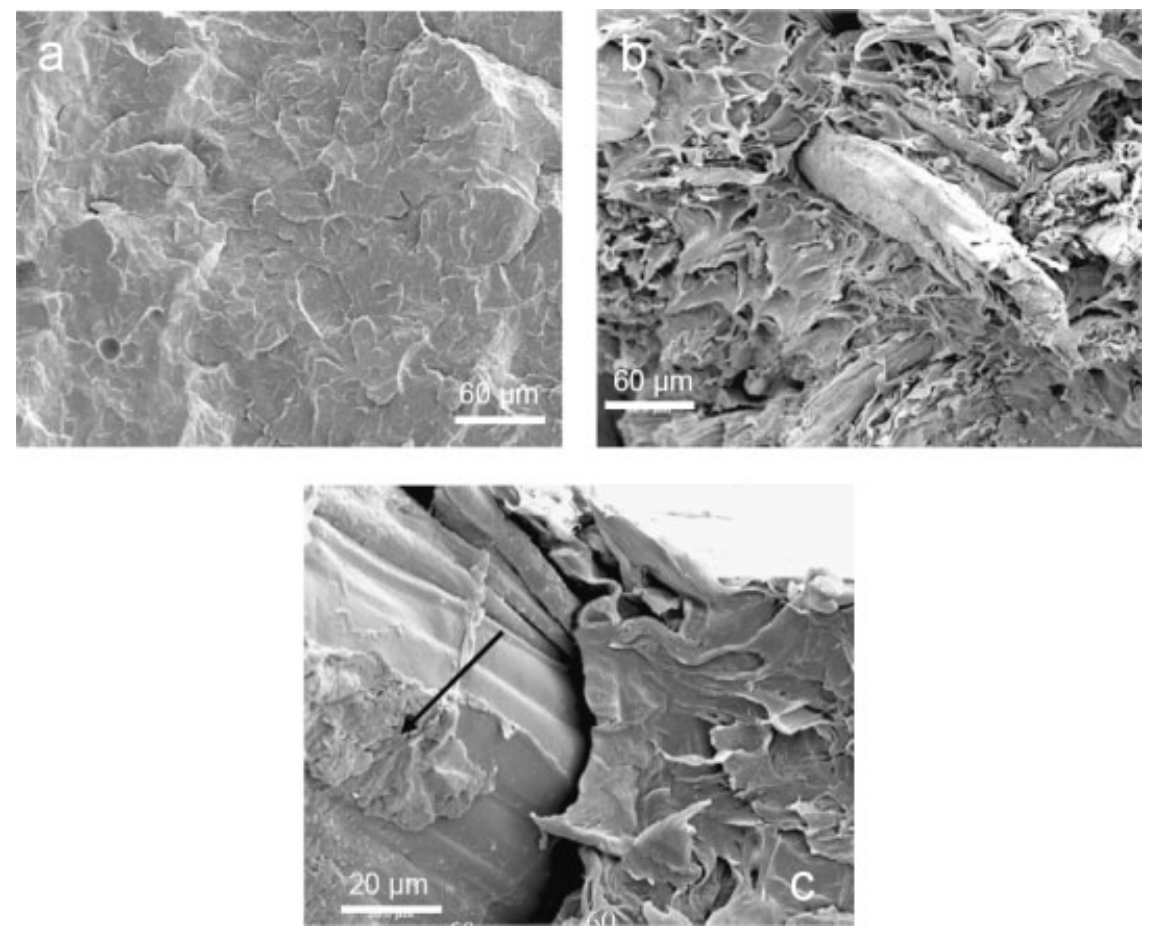

Figure 2. Scanning electron micrograph of freshly fractured surface of rachis/PP composites: (a) unfilled matrix, (b) $25 \mathrm{wt} .-\%$ of raw fibers, and (c) $50 \mathrm{wt} .-\%$ of extracted fibers. 

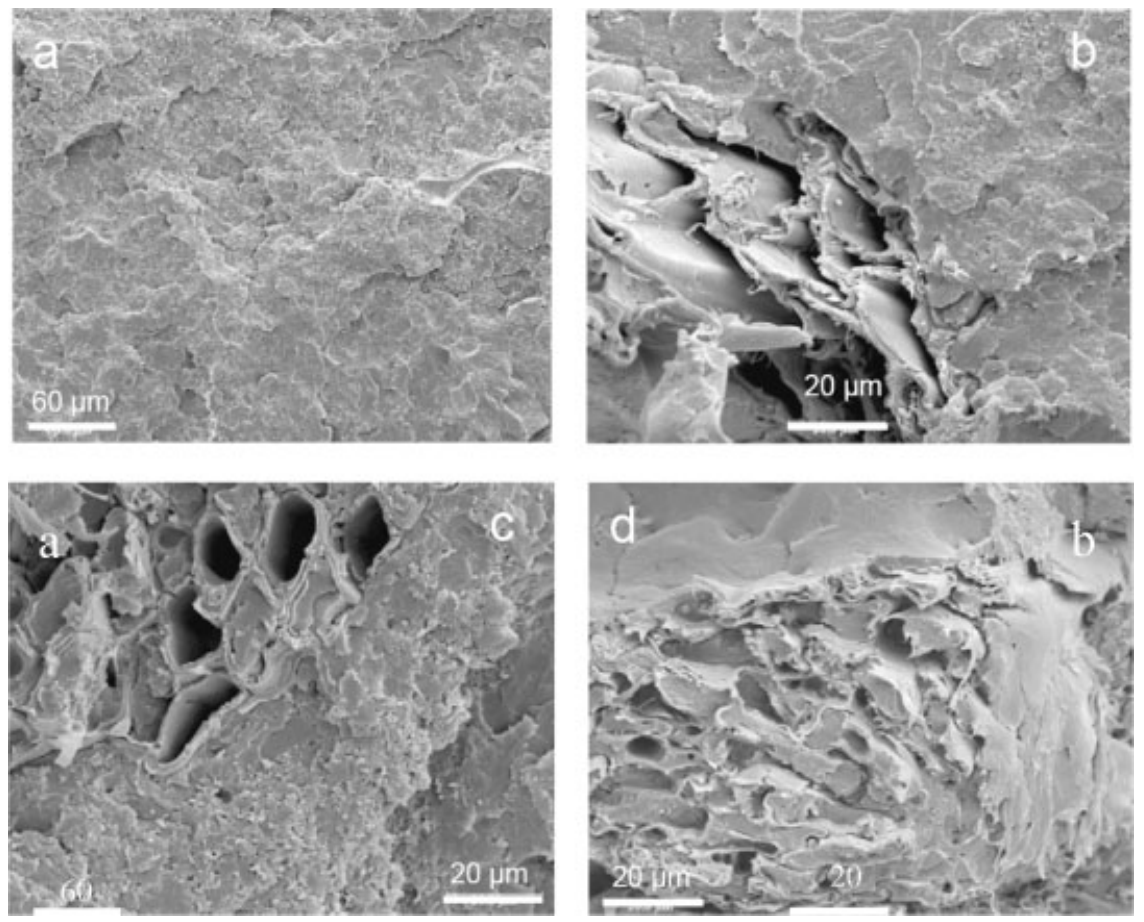

Figure 3. Scanning electron micrograph of freshly fractured surface of rachis/MAPP composites: (a) unfilled matrix, (b) $25 \mathrm{wt} .-\%$ of raw fibers, (c) $25 \mathrm{wt} .-\%$ of extracted fibers, and (d) $50 \mathrm{wt} .-\%$ of extracted fibers.

indicates that the interfacial adhesion between the lignocellulosic filler and the matrix was poor. The absence of any physical contact between both components is shown by the holes and spacing occurrence in the matrix as well as along the lignocellulosic filler. This observation could be explained by the polar nature of the surface of the lignocellulosic filler. ${ }^{[26]}$ When the rachis fibers are extracted (Figure 2c) the interfacial adhesion seems to remain poor. However, the presence of adhering matrix domains on the fiber (indicated by an arrow) is observed.

Using a MAPP matrix, the SEM micrographs (Figure 3) of investigated composite specimens seem to provide evidence of a good lignocellulosic filler dispersion within the matrix, effective wetting of lignocellulosic filler by the matrix and stronger interfacial adhesion between the components (Figure $3 b-3 d$ ). The fractured surface was much less chaotic and the samples did not cleave under fracture. The MAPP matrix provided a good wetting, which can be observed by the absence of holes around the lignocellulosic fillers and from the breaking of lignocellulosic fillers during fracture. In the case of extracted fibers (Figure $3 \mathrm{c}$ and $3 \mathrm{~d}$ ) part of the holes resulting from the removal of extractives are still present in the composite. The differences between PP and MAPP-based composites are ascribed to the presence of the polar ring in MAPP derived from maleic anhydride grafting. The polar character of the surface of the lignocellulosic rachis material, studied by contact angles and Inverse Gas Chromatography (IGC) measurements, supports these results. ${ }^{[26]}$
SEM micrographs (not shown) of the laminated composite materials composed by two perpendicular plies of rachis fibers did not show significant differences in terms of filler and PP matrix interactions. Optical microscopy observations (not shown) indicated that the embedded fibers roughly retained their previous orientation within the PP matrix.

\section{Thermal Analysis}

DSC measurements were performed to characterize the thermal behavior of banana tree lignocellulosic filler filled PP or MAPP films. Typical DSC thermograms recorded during heating and cooling scans for neat PP and related rachis-based composites filled with $25 \mathrm{wt} .-\%$ and $50 \mathrm{wt} .-\%$ of raw fibers and $25 \mathrm{wt} .-\%$ of extracted rachis are displayed in Figure 4. For each specimen an endothermal or exothermal peak was observed during the heating or cooling temperature scan, respectively. It was ascribed to the melting or formation of crystalline domains of the polymeric matrix.

The thermal characteristics $\left(T_{\mathrm{m}}, T_{\mathrm{m}}, \Delta H_{\mathrm{m}}\right.$, and $\left.X_{\mathrm{c}}\right)$ determined or calculated from DSC scans are collected in Table 1 . The degree of crystallinity of the samples was determined using Equation (1) and then accounted for the effective matrix amount in the composites. By comparing the characteristics of neat matrices, it is observed that $T_{\mathrm{m}}$ is similar whereas $T_{\mathrm{c}}$ is higher for MAPP. The former is directly linked to the size of the crystalline domains. The 


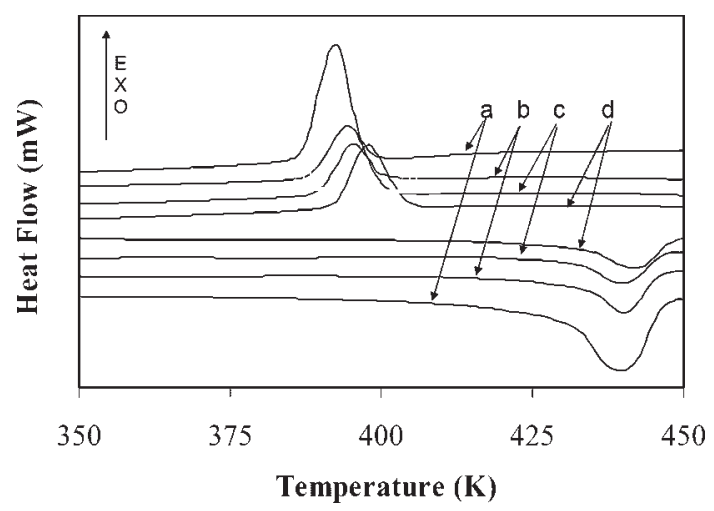

Figure 4. DSC thermograms recorded during heating (bottom curves) and cooling (top curves) of rachis/PP composites: (a) unfilled matrix, (b) $25 \mathrm{wt} .-\%$ and (c) $50 \mathrm{wt} .-\%$ of raw fibers, and (d) $50 \mathrm{wt} .-\%$ of extracted fibers.

degree of crystallinity of the unfilled PP is much higher $(46 \%)$ than that of the pure MAPP matrix $(33 \%)$. This is ascribed to the copolymerization process with maleic anhydride moieties which reduces the regularity of the macromolecular chains and then their ability to crystallize.

For PP-based composites, the $T_{\mathrm{m}}$ is unaffected by the presence of the lignocellulosic filler, regardless its content and the treatment to which it was submitted. This is an indication that the size of the crystalline domains is retained. The degree of crystallinity is found to significantly decrease upon filler addition, especially at high filler loading (50 wt.-\%) indicating that high amounts of filler can limit the organization of the matrix. This phenomenon seems to be more significant with raw rachis fibers, indicating that extractives present in the filler could have a negative effect on the crystallization capability of the PP

Table 1. Characteristics of the calorimetric transitions of rachis fibers filled composites using data obtained from the DSC curves: $T_{\mathrm{m}}$ and associated $\Delta H_{\mathrm{m}}, T_{\mathrm{c}}$ and $X_{\mathrm{c}}$ (calculated from $\Delta H_{\mathrm{m}}$ values).

\begin{tabular}{|c|c|c|c|c|c|c|}
\hline & Filler & $\begin{array}{l}\text { Fiber } \\
\text { content }\end{array}$ & $T_{\mathrm{m}}$ & $\Delta H_{\mathrm{m}}$ & $T_{\mathrm{c}}$ & $X_{\mathrm{c}}{ }^{\text {a) }}$ \\
\hline & & wt.- $\%$ & ${ }^{\circ} \mathrm{C}$ & $\mathrm{J} \cdot \mathrm{g}^{-1}$ & ${ }^{\circ} \mathrm{C}$ & $\%$ \\
\hline PP matrix & - & 0 & 166 & 95.5 & 104 & 46 \\
\hline & Raw fibers & 25 & 166 & 65.0 & 108 & 42 \\
\hline & & 50 & 167 & 21.4 & 122 & 21 \\
\hline & Extracted fibers & 25 & 167 & 70.9 & 125 & 45 \\
\hline & & 50 & 167 & 31.1 & 131 & 30 \\
\hline & $\begin{array}{l}\text { Treated fibers } \\
\quad \text { (laminated) }\end{array}$ & 19 & 170 & 37.4 & 116 & 36 \\
\hline MAPP matrix & - & 0 & 165 & 68.4 & 110 & 33 \\
\hline & Raw fibers & 25 & 165 & 50.9 & 120 & 33 \\
\hline & & 50 & 165 & 21.2 & 132 & 20 \\
\hline & Extracted fibers & 25 & 163 & 57.2 & 124 & 37 \\
\hline & & 50 & 163 & 31.3 & 132 & 30 \\
\hline
\end{tabular}

a) $X_{\mathrm{c}}=\frac{\Delta H_{\mathrm{m}}}{\Delta H^{\mathrm{o}}} \times \frac{100}{w}$, where $\Delta H_{\mathrm{m}}^{\mathrm{o}}=207 \mathrm{~J} \cdot \mathrm{g}^{-1}$ is the heat of fusion for $100 \%$ crystalline PP and $w$ is the weight fraction of polymeric matrix material in the composite. matrix. The $T_{\mathrm{c}}$ is significantly higher for composites than for the unfilled matrix and it is found to increase with the filler loading. This effect seems to be more pronounced for extracted rachis fibers. The increase in $T_{\mathrm{c}}$ values can be explained by the assumption that lignocellulosic filler act as an efficient nucleating agent for the crystallization of the polymeric matrix. Indeed, it is well known that the crystallization rate can be affected by the surface topography of the fibers. Based on SEM observations, it seems that the presence of extractives on the fiber surface hinder the nucleation of crystalline domains during cooling. Similar trends were reported for MAPP-based composites.

\section{$D M A$}

Dynamic mechanical measurements were performed for unfilled PP and MAPP and related composite materials filled with 25 and 50 wt.- $\%$ of lignocellulosic fibers. The curve of the dependence of the storage tensile modulus, $E^{\prime}$, and loss angle tangent, $\tan \delta$, vs. temperature at $1 \mathrm{~Hz}$ is displayed in Figure 5 and 6 for PP and MAPP based composites, respectively. The storage modulus (Figure 5a and $6 \mathrm{a}$ ) was normalized at $1 \mathrm{GPa}$ at low temperature, i.e. $200 \mathrm{~K}$, for all compositions in order to minimize the error induced from the determination of sample dimensions and
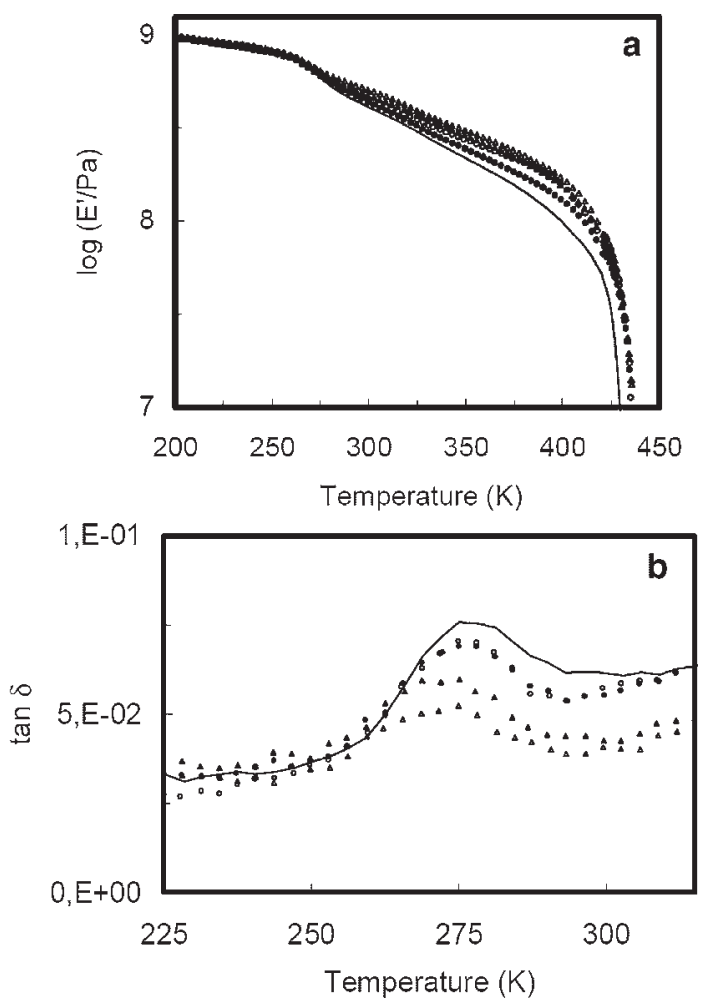

Figure 5. (a) Logarithm of the storage tensile modulus $E^{\prime}$, and (b) loss angle tangent $\tan \delta$, vs. temperature at $1 \mathrm{~Hz}$ for rachis/PP composites: unfilled PP matrix (continuous line), 25 wt.-\% (O) and $50 \mathrm{wt} .-\%(\bigcirc)$ of raw fibers, and $25 \mathrm{wt} .-\%(\sigma)$ and $50 \mathrm{wt.}-\%(\triangle)$ of extracted fibers. 

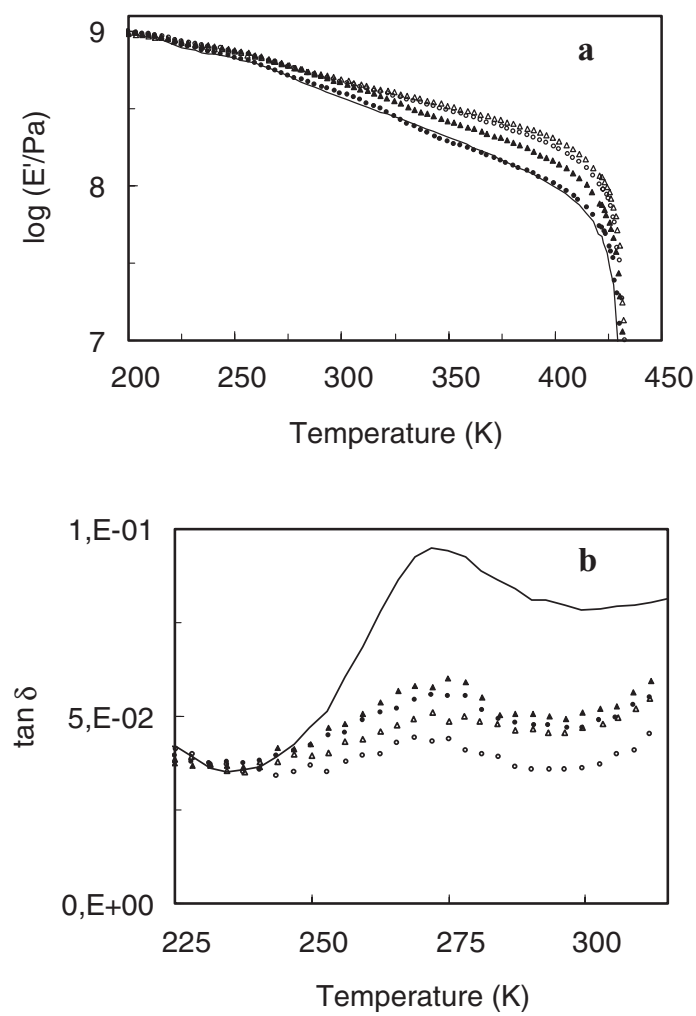

Figure 6. (a) Logarithm of $E^{\prime}$, and (b) $\tan \delta$, vs. temperature at $1 \mathrm{~Hz}$ for rachis/MAPP composites: unfilled PP matrix (continuous line), 25 wt.- $\%(\bigcirc)$ and 50 wt.- $\%(\bigcirc)$ of raw fibers, and 25 wt.- $\%$ $(\sigma)$ and 50 wt.- $\%(\triangle)$ of extracted fibers.

allow better comparison between each material. This procedure can be justified by the fact that the difference between the elastic modulus of the glassy polymer and lignocellulosic filler is not high enough to easily appreciate any change in this temperature range.

The curves corresponding to the unfilled PP and MAPP matrices are typical of semi-crystalline thermoplastic behavior. The loss angle curves (Figure $5 \mathrm{~b}$ and $6 \mathrm{~b}$ ) display a relaxation process around $275 \mathrm{~K}$ associated with the anelastic manifestation of the glass-rubber transition of the amorphous domains of the polymer. This transition was not observed from DSC measurements because of the relatively high degree of crystallinity of the materials, resulting in a weak heat flow increment at $T_{\mathrm{g}}$. It can also be evidenced in Figure 5a and 6a from the weak modulus drop associated with the softening of these amorphous chains. The high storage modulus values reported are ascribed to the reinforcing and cross-linking effects of the crystalline regions in the rubbery state. It is observed that the storage modulus decreases slightly with increasing temperature. The storage modulus was found to be systematically higher for PP than for MAPP for a given temperature owing to the lower degree of crystallinity of the copolymer observed from DSC measurements. At higher temperatures the modulus drops sharply and irremediably due to the melting of the
Table 2. Mechanical properties of rachis fibers filled composites using data obtained from tensile tests: tensile modulus, $E$, tensile strength, $\sigma_{\mathrm{b}}$, and ultimate strain, $\varepsilon_{\mathrm{b}}$.

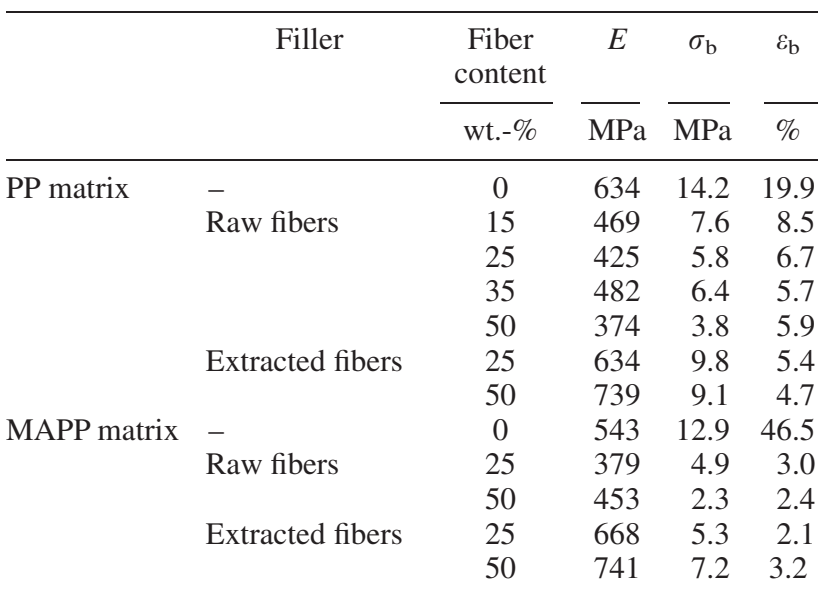

crystalline domains around $440 \mathrm{~K}$. This value agrees with melting temperature measured from DSC analysis.

When filled with 25 (filled circles) or 50 wt.- $\%$ of raw rachis filler (open circles), the rubbery modulus of PP increases (Figure 5a). For instance the storage modulus at $370 \mathrm{~K}$ is around $0.17 \mathrm{GPa}$ for the neat PP matrix and it is around 0.20 and $0.23 \mathrm{GPa}$ for composites filled with 25 and $50 \mathrm{wt} .-\%$ of lignocellulosic filler, respectively. Because the degree of crystallinity of composites was found to decrease upon filler addition (Table 2), the increase in the rubbery storage modulus for composites should be ascribed to a reinforcing effect of the lignocellulosic filler. This effect is more significant with extracted rachis and the storage modulus at $370 \mathrm{~K}$ increases up to 0.23 and 0.26 for composites filled with 25 (filled triangles) and $50 \mathrm{wt} .-\%$ of extracted lignocellulosic filler (open triangles), respectively. Therefore, the removal of extractives seems to have a beneficial effect on the mechanical properties of the composite. It could be, at least partially, ascribed to the perforated structure of treated fibers, which results in a higher volume fraction of filler for a given weight content. It can also be assumed that some extractives could be released during processing and consequently acted as lubricating agents. In addition, a slight increase of the thermal stability of PP is observed upon filler addition.

The magnitude of the relaxation process associated with the glass-rubber transition of the PP matrix decreases for composites (Figure 5b). It is ascribed to both a reduction of the number of mobile units participating to the relaxation process and to the mobility of these units. This effect is more significant for extracted rachis filler. The number of possible mobile units proportional to the volume fraction of polymeric matrix is the lower, the higher the volume fraction of fibers is. Especially for MAPP-based composites, the presence of the filler leads to decreasing mobility of the polymer chains due to the expected 
pronounced fiber-matrix coupling. In addition, a slight decrease of the temperature position of the relaxation peak is observed. It is associated to the well-known mechanical coupling effect.

Similar observations can be drawn for MAPP-based composites (Figure 6). For instance the storage modulus at $370 \mathrm{~K}$ is around $0.15 \mathrm{GPa}$ for the unfilled MAPP matrix and it is around 0.25 and $0.28 \mathrm{GPa}$ for composites filled with 50 wt.- $\%$ of raw and extracted lignocellulosic filler, respectively. The higher decrease of the magnitude of the loss angle upon filler addition (Figure 6b) for MAPP-based composites compared to PP-based materials is an indication of stronger interfacial adhesion. This result corroborates with SEM observations.

Figure 7 displays the evolution of the storage tensile modulus vs. temperature for bidirectional treated long rachis fibers reinforced PP (laminated composites). The curve corresponding to the unfilled PP matrix is added as reference. The rubbery modulus of the composite at $370 \mathrm{~K}$ is around $0.35 \mathrm{GPa}$, although the filler content is lower (19 wt.-\%) than for short fibers reinforced PP composites (it was 0.20 and 0.23 for PP-based composites reinforced with 25 wt. $-\%$ of raw and extracted fibers, respectively). It is well known that the aspect ratio is an important factor controlling the mechanical performances of fibers based
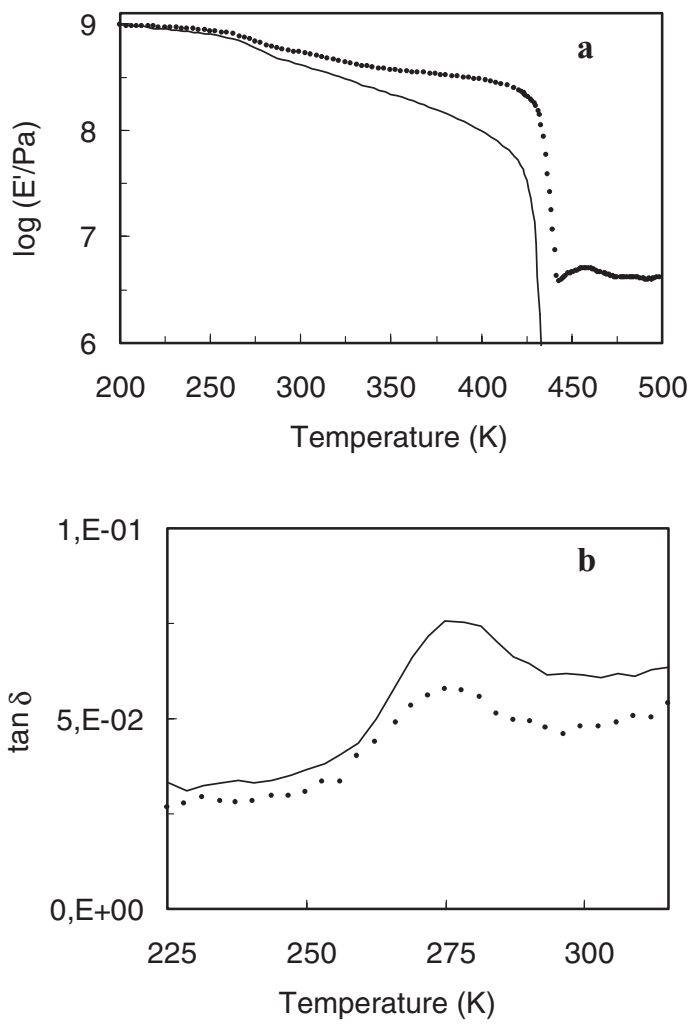

Figure 7. (a) Logarithm of $E^{\prime}$, and (b) $\tan \delta$, vs. temperature at $1 \mathrm{~Hz}$ for treated rachis fibers/PP laminated composites: unfilled PP matrix (continuous line), and 19 wt.- $\%$ composite $(\mathcal{O})$. composites. The mechanical treatment of rachis obtained from the prototype barking machine and resulting thinning effect should also plays a role on the observed reinforcing effect. In addition, after melting of the matrix the modulus of the laminated composite remains roughly constant around $4 \mathrm{MPa}$ up to $500 \mathrm{~K}$. At this temperature cellulose starts to degrade and the modulus drops sharply.

\section{High Strain Behavior (Nonlinear Conditions)}

The effect of fiber loading on tensile high-strain behavior PP or MAPP-based composites was investigated up to the break. The tensile or Young's modulus was determined from the slope of the stress vs. strain curves in the vicinity of $\sigma=\varepsilon=0$, i.e. for $\varepsilon<1 \%$. Results are collected in Table 2 . The MAPP matrix displays both a lower modulus and lower strength than the PP matrix as a result of its lower degree of crystallinity as reported from both DSC and DMA measurements. The elongation at break is consequently and obviously higher for MAPP than for PP homopolymer. Figure 8 shows the relative mechanical properties of the composites, viz. tensile modulus, tensile strength and elongation at break. These characteristics were obtained by dividing the property of a given material by the one of the unfilled PP or MAPP matrix.

The addition of raw rachis lignocellulosic filler within the PP matrix results in a dramatic decrease of the mechanical performances of the material. All the mechanical characteristics decrease continuously. The decrease of the tensile modulus upon filler addition seems to disagree with DMA observations. However, it is worth noting that because DMA analysis involves weak stresses, the adhesion between the filler and the matrix is not damaged. Under higher stress, as used for tensile tests, the adhesion is involved. This result is therefore an indication of the lack of intimate adhesion between both components of the composite structure.

When using extracted rachis as the reinforcing phase in PP, an increase of the tensile modulus is observed. This could be ascribed to the perforated structure of treated fibers, which results in a higher volume fraction of filler for a given weight content. But the most probable explanation should be related to a surface phenomenon. Extractives, although mainly located within the fibers, can most probably form a low modulus thin layer at the surface of the fiber. This thin layer should decrease the efficiency of the stress transfer at the filler/matrix interface under mechanical solicitation. For a given composition, the strength increases and the elongation at break decreases when using extracted rachis filler rather that raw filler. This can be also ascribed to an interfacial phenomenon. The well-known decrease in elongation at break upon addition of rigid fillers arises from the fact that the actual elongation experienced by the polymeric matrix is much higher than the elongation measured for the specimen. 

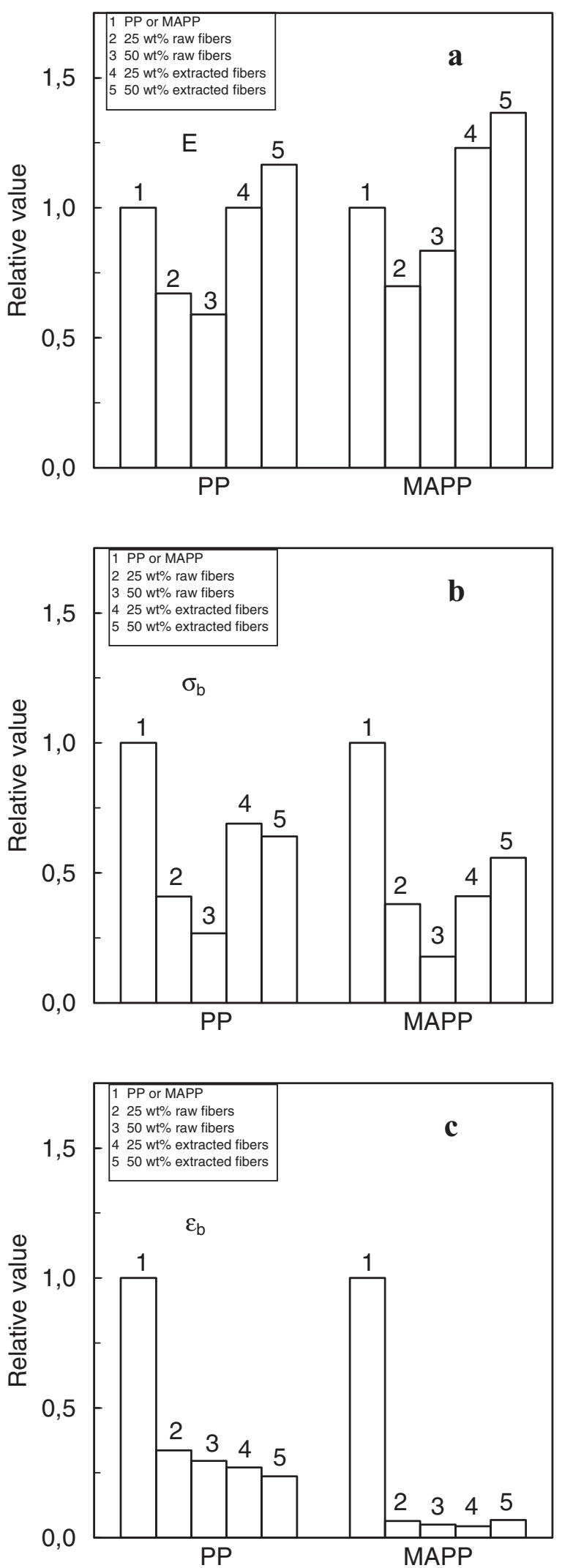

Figure 8. Relative mechanical properties for rachis/PP and rachis MAPP composites: (a) tensile modulus $(E)$, (b) tensile strength $\left(\sigma_{\mathrm{b}}\right)$ and (c) elongation at break $\left(\varepsilon_{\mathrm{b}}\right)$.
Similar trends were observed for MAPP-based composites. When using extracted rachis fibers, the modulus is higher for a given composition than for its PP-based counterpart. The decrease reported for the strength is due to the dramatic decrease of the elongation at break for MAPPbased composites. Again, this phenomenon is associated with stronger interfacial adhesion between the lignocellulosic filler and the MAPP matrix.

\section{Water Absorption}

The absorption of water for the different composite specimens conditioned in a 98\% RH atmosphere was evaluated as a function of time as described in the Experimental Section. The results are shown in Figure $9 \mathrm{a}$ and $9 \mathrm{~b}$ for PP and MAPP based composites, respectively. These swelling data are mean of several trials, and the reliability of measurements was very good. Some general and standard remarks can be made: (i) all the composites absorb water during the experiment, but following different behaviors;
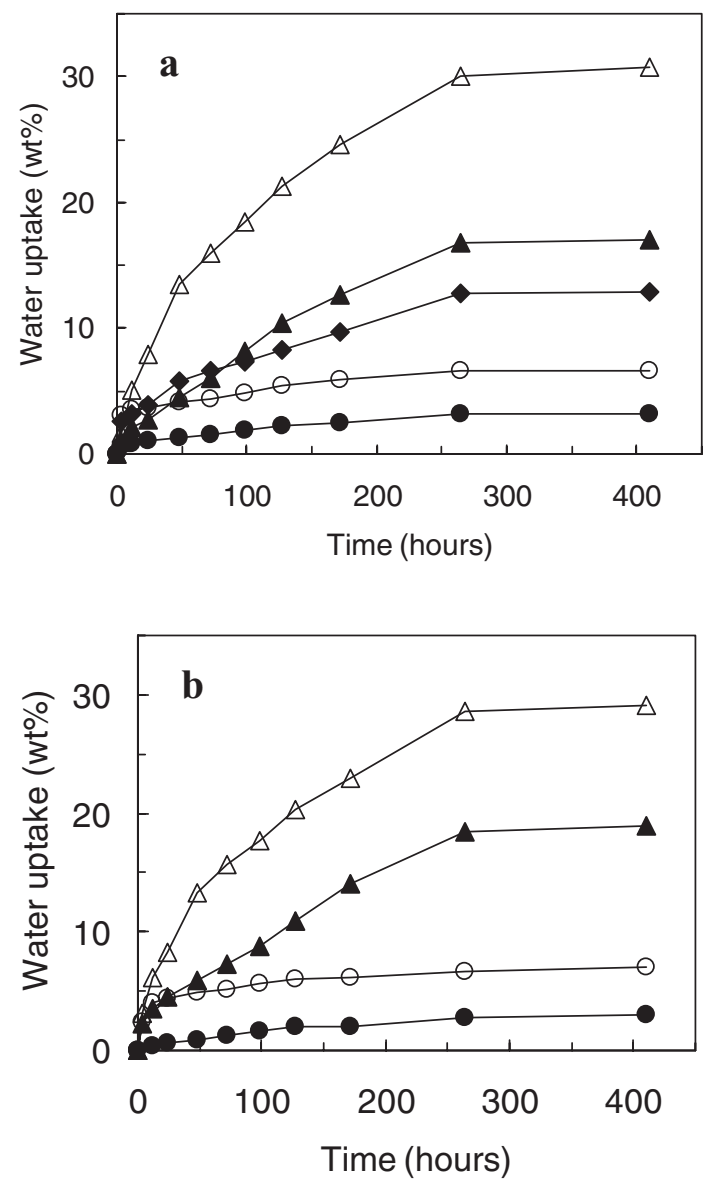

Figure 9. Water uptake versus time for (a) PP and (b) MAPPbased composites conditioned at $98 \% \mathrm{RH}$ and filled with $25 \mathrm{wt} .-\%$

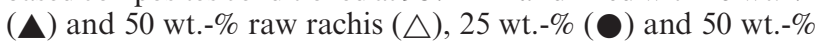
extracted rachis $(\bigcirc)$, and 19 wt.- $\%$ long rachis fibers $(\diamond)$. The solid lines serve to guide the eye. 
(ii) the existence of two well-separated regions is reported. In region I, at lower times, the kinetics of absorption is fast, and in region II, at extended times, the kinetics of absorption is slow and leads to a plateau which value corresponds to the water absorption at equilibrium.

The water diffusivity or diffusion coefficient, $D$, of water in the different composites was estimated using Equation (3) for short time experimental data and the maximum water absorption (or water absorption at equilibrium) was ascribed to the longer time experimental data $(17 \mathrm{~d})$. The plots of $\left(M_{\mathrm{t}}-M_{0}\right) / M_{\infty}$ as a function of $\left(t / L^{2}\right)^{1 / 2}$ were performed for all the composites. The $D$ values were calculated from the slope of these plots and results are collected in Table 3 with the water uptake equilibrium values $\left(W U_{\infty}\right)$.

By comparing the values reported for neat matrices, it is observed that both the $D$ and $W U_{\infty}$ values are very low. It is ascribed to the non-polar character of the material. When increasing the amount of lignocellulosic filler in the composite, these values increase significantly. The $D$ values are of the same order of magnitude as those reported for Opuntia ficus-indica reinforced PP composites conditioned at $98 \%$ RH. ${ }^{[15]}$ For raw rachis filled materials, the water diffusion coefficient and water uptake at equilibrium are almost independent on the nature of the matrix. This is an indication that the water sensitivity is mainly governed by the filler. For extracted fibers again no difference is reported with respect to the nature of the matrix. However, the extraction step results in a significant decrease of both $D$ and $W U_{\infty}$ values. It could be ascribed to a higher water sensitivity of the extractives present in the filler.

However, it is well established that the diffusivity of water is strongly influenced by the structure of the material, such as the porosity that can develop during drying, and also by the water affinity of the polymer components. ${ }^{[27]}$ In addition, if the adhesion level between the filler and the matrix is not good enough, a diffusion pathway can exist. The existence of such a pathway is also related to the filler connection and therefore to its percolation threshold. In order to evidence the effect of porosity, we present in Table 3 (data in square brackets) the water uptake values predicted from a simple mixing rule taking into account the composition of the sample and the water uptake of the neat matrix and of the lignocellulosic filler. The latter data was obtained from water absorption experiments performed on the fibers. These values are 30, 13 and $25 \%$ for the raw, extracted and treated fibers, respectively. It is clear by comparing experimental and predicted data of $W U_{\infty}$ (Table 3), that the experimental data are much higher than the predicted ones for raw and treated fibers based composites. This is an indication of the high porosity level in these materials, mainly due to the lack of adhesion between both components. On the contrary, the experimental data agree rather well with predicted values for extracted fibers based materials. This is attributed to a higher adhesion between the matrix and the filler in agreement with other experimental observations. No significant differences are reported when using either PP or MAPP as matrix, showing that the main aspect involved in the adhesion is the presence or the absence of extractives.

The water sensitivity of rachis based composites was also characterized by immersing samples in distilled water at room temperature. The water uptake at equilibrium of soaked materials was determined from Equation (2) when stabilization of the sample weight was observed and the values obtained are collected in Table 3 . This equilibrium was reached after $3 \mathrm{~d}$ immersion in water. It is worth noting that this duration is significantly shorter than for $98 \% \mathrm{RH}$ conditioned samples $(17 \mathrm{~d})$. The water uptake values are higher for soaked samples than for highly moist atmosphere conditioned materials. Again, it is observed that raw fiber based composites are much more sensitive to water than

Table 3. $\quad D$ and $W U_{\infty}$ for PP and MAPP based composites when conditioned at $98 \% \mathrm{RH}$ or immersed in water.

\begin{tabular}{|c|c|c|c|c|c|}
\hline & \multirow[t]{3}{*}{ Filler } & \multirow{3}{*}{$\frac{\text { Fiber content }}{\text { wt. }-\%}$} & \multicolumn{2}{|c|}{$98 \% \mathrm{RH}$} & \multirow{3}{*}{$\begin{array}{c}\text { Water immersion } \\
\frac{W U_{\infty}}{\%}\end{array}$} \\
\hline & & & $W U_{\infty}^{a)}$ & $D$ & \\
\hline & & & $\%$ & $\mathrm{~cm}^{2} \cdot \mathrm{s}^{-1} \times 10^{8}$ & \\
\hline \multirow[t]{6}{*}{ PP matrix } & - & 0 & 0.31 & 0.026 & - \\
\hline & Raw fibers & 25 & $16.7[7.7]$ & 0.448 & 27.8 \\
\hline & & 50 & $30.1[15.2]$ & 1.18 & 50.6 \\
\hline & Extracted fibers & 25 & $3.2[3.5]$ & 0.396 & 4.1 \\
\hline & & 50 & $6.6[6.7]$ & 0.930 & 10.2 \\
\hline & Treated fibers (laminated) & 19 & $12.8[5.0]$ & 0.557 & 37.9 \\
\hline \multirow[t]{5}{*}{ MAPP matrix } & - & 0 & 0.24 & 0.043 & - \\
\hline & Raw fibers & 25 & $18.5[7.7]$ & 0.472 & 20.9 \\
\hline & & 50 & $28.6[15.1]$ & 1.01 & 32.4 \\
\hline & Extracted fibers & 25 & $2.8[3.4]$ & 0.345 & 3.2 \\
\hline & & 50 & $6.6[6.6]$ & 0.990 & 10.4 \\
\hline
\end{tabular}

a) The data in square brackets correspond to data predicted from a mixing rule taking into account the composition of the sample and the water uptake of the neat matrix and lignocellulosic filler. 
extracted fiber based materials. In contrast to the conditioning of the samples in a $98 \%$ RH atmosphere, the immersion of the materials in water can cause the removal of extractible compounds. The influence of this phenomenon was supposed to be limited due to the correction performed and described in the Experimental Section.

\section{Conclusion}

Composite materials were prepared by compounding and hot-pressing natural fibers and PP. The lignocelulosic filler was extracted from the rachis of Musa acuminate Colla var. Dwarf Cavendish banana tree. It was used as raw filler or after a chemical treatment with acetone, ethanol/ toluene and water, assuming to have removed most of the extractible compounds, i.e. lignin and fatty substances. Mechanically isolated fibers were also obtained from a prototype barking machine and used to process laminated long fiber composite materials. MAPP was used as matrix to tentatively promote interfacial adhesion between both constituents of the composite.

The morphological investigation of the fibers and resulting composites was performed using SEM. After removal of extractible components, the structure of the fiber is less compact and the presence of cylindrical holes corresponding to their localization is clearly stated. Investigations of freshly fractured surfaces of composite materials evidence the poor interfacial adhesion between the raw filler and the PP matrix. Stronger interactions are reported with extracted fibers or when using MAPP as matrix.

Thermal properties of the composites were evaluated by DCS. A decrease of the degree of crystallinity of the matrix was observed when increasing the amount of lignocellulosic filler, mainly with raw fibers, showing that the filler limits the organization of the matrix. However, the lignocellulosic filler, and especially the extracted fibers, seems to act as a nucleating agent as evidenced from the increase of the crystallization temperature. Mechanical investigation of composites in the linear range with dynamic mechanical measurements shows a reinforcing effect of the filler in the rubbery state of the matrix. A thermal stabilization of the composite modulus was observed after melting of the matrix when using long fibers. Tensile tests, which are more sensitive to the adhesion level between components, were also performed. They showed that the main aspect involved in the interfacial adhesion between the polar filler and the non-polar matrix is the extraction of lignin and fatty substances. Water absorption experiments were performed by either conditioning the sample in a highly moist atmosphere or soaking it in distilled water. Raw fibers based composites were found to be much more sensitive to water absorption than extracted fibers based materials. This was ascribed to the poorer adhesion between the matrix and the raw filler compared to extracted fibers.

[1] A. K. Bledzki, J. Gassan, Prog. Polym. Sci. 1999, 24, 221.

[2] S. J. Eichhorn, C. A. Baillie, N. Zafeiropoulos, L. Y. Mwaikambo, M. P. Ansell, A. Dufresne, K. M. Entwistle, P. J. Herrera-Franco, G. C. Escamilla, L. Groom, M. Hugues, C. Hill, T. G. Rials, P. M. Wild, J. Mater. Sci. 2001, 36, 2107.

[3] D. Puglia, J. Biagiotti, J. M. Kenny, Nat. Fibers 2004, 1, 37.

[4] Y. Li, Y. W. Mai, L. Ye, Compos. Sci. Technol. 2000, 60, 2037.

[5] K. L. Fung, X. S. Xing, R. K. Y. Li, S. C. Tjong, Y. W. Mai, Compos. Sci. Technol. 2003, 63, 1255.

[6] L. Y. Mwaikambo, E. Martuscelli, M. Avella, Polym. Test. 2000, 19, 905 .

[7] K. Okubo, T. Fujii, Y. Yamamoto, Composites: Part A 2004, $35,377$.

[8] J. Simonsen, Constr. Build. Mater. 1996, 10, 435.

[9] K. Oksman, L. Wallstrom, L. A. Berglund, R. D. T. Filho, J. Appl. Polym. Sci. 2002, 84, 2358.

[10] T. Nishino, K. Hirao, M. Kotera, K. Nakamae, H. Inagaki, Compos. Sci. Technol. 2003, 63, 1281.

[11] S. K. Ozaki, M. B. B. Monteiro, H. Yano, Y. Imamura, M. F. Souza, Polym. Degrad. Stab. 2005, 87, 293.

[12] V. N. Hristov, R. Lach, W. Grellmann, Polym. Test. 2004, 23, 581.

[13] M. N. Anglès, J. Salvadó, A. Dufresne, J. Appl. Polym. Sci. 1999, 74, 1962.

[14] A. Dufresne, D. Dupeyre, M. Paillet, J. Appl. Polym. Sci. 2003, 87, 1302 .

[15] M. E. Malainine, M. Mahrouz, A. Dufresne, Macromol. Mater. Eng. 2004, 289, 855.

[16] S. Mishra, J. B. Naik, Polym. Plast. Technol. Eng. 1999, 60, 1729.

[17] S. Mishra, J. B. Naik, Y. P. Patil, Compos. Sci. Technol. 2000, 60, 1729

[18] S. Joseph, M. S. Sreekala, Z. Oommen, P. Koshy, S. Thomas, Compos. Sci. Technol. 2002, 62, 1857.

[19] R. Agarwal, N. S. Saxena, K. B. Sharma, S. Thomas, L. A. Pothan, Ind. J. Pure Appl. Phys. 2003, 41, 448.

[20] L. A. Pothan, Z. Oommen, S. Thomas, Compos. Sci. Technol. 2003, 63, 283.

[21] L. A. Pothan, N. R. Neelakantan, B. Rao, S. Thomas, J. Reinf. Plast. Compos. 2004, 23, 153.

[22] J. B. Naik, S. Mishra, Polym. Plast. Technol. Eng. 2004, 43, 1085.

[23] L. A. Pothan, S. Thomas, J. Appl. Polym. Sci. 2004, 91, 3856.

[24] H. Savastano Jr., P. G. Warden, R. S. P. Coutts, Cem. Concr. Compos. 2000, 22, 379.

[25] J. M. Vergnaud, "Liquid Transport Process in Polymeric Materials: Modeling and Industrial Applications", Prentice-Hall, Englewood Cliffs, NJ 1991.

[26] N. Cordeiro, M. N. Belgacem, I. C. Torres, J. C. V. P. Moura, Ind. Crops Prod. 2004, 19, 147.

[27] S. N. Marousis, V. T. Karathanos, G. D. Saravacos, J. Food Process. Preserv. 1999, 15, 183. 